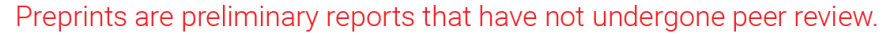 \\ They should not be considered conclusive, used to inform clinical practice, or referenced by the media as validated information. \\ Potential function and molecular mechanism of circRNAs involved in idiopathic pulmonary fibrosis
}

\section{Fangwei Li}

Lanzhou University Second Hospital https://orcid.org/0000-0002-4176-3528

\section{Hong Wang}

No. 82, Cuiying Men, Lanzhou

\section{Hongyan Tao}

No. 82, Cuiying Men, Lanzhou

\section{Fanqi Wu}

No. 82, Cuiying Men, Lanzhou

\section{Dan Wang}

No. 82, Cuiying Men, Lanzhou

Yixin Wan ( $\square$ wanyixinzr@163.com )

No. 82, Cuiying Men, Lanzhou

\section{Research}

Keywords: circular RNAs, Idiopathic pulmonary fibrosis, miRNA response elements, RNA-binding proteins, Open reading frames

Posted Date: February 29th, 2020

DOI: https://doi.org/10.21203/rs.3.rs-15519/v1

License: (c) (i) This work is licensed under a Creative Commons Attribution 4.0 International License.

Read Full License 


\section{Abstract}

Background: Recent studies have found a regulatory role of circular RNAs (circRNAs) in the pathogenesis of idiopathic pulmonary fibrosis (IPF). However, the function and underlying molecular mechanism of circRNAs involved in IPF are uncertain and incomplete. This study aimed to further provide some critical information for the circRNA function in IPF using bioinformatic analysis.

Methods: We searched in the NCBI (National Center for Biotechnology Information) Gene Expression Omnibus (GEO) database to find the circRNA expression profiles of human IPF. The microarray data GSE102660 was obtained and differentially expressed circRNAs were identified through R software.

Results: 6 significantly up-regulated and 13 significantly down-regulated circRNAs were identified involved in the pathogenesis of IPF. The binding sites of miRNAs for each differentially expressed circRNA were also predicted and circRNA-miRNA-mRNA networks were constructed for the most upregulated hsa_circ_0004099 and down-regulated hsa_circ_0029633. In addition, GO and KEGG enrichment analysis revealed the molecular function and enriched pathways of the target genes of circRNAs in IPF.

Conclusion: These findings suggest that candidate circRNAs might serve an important role in the pathogenesis of IPF. Therefore, these circRNAs might be potential biomarkers for diagnosis and promising targets for treatment of IPF, which still need further verification in vivo and in vitro.

\section{Background}

Idiopathic pulmonary fibrosis (IPF) is a specific form of chronic, progressive, and irreversible interstitial lung disease (ILD) of unknown cause [1], regarded as a consequence of multiple interacting genetic and environmental risk factors, which leads to myofibroblast activation and consequent abnormal accumulation of extracellular matrix [2]. Patients with IPF generally suffer progressive dyspnea, a decline in lung function, decreased activity tolerance and poor quality of life [3-5]. Since current antifibrotic treatment can only delay disease progression to some extent but does not cure the disease itself, the prognosis of IPF is poor, with a 5 -year survival rate between $20 \%$ and $40 \%$, which is lower than many tumors [6-8]. Therefore, it is important to explore the molecular mechanisms responsible for IPF, aiming to find new methods to prevent and treat IPF.

Circular RNAs (circRNAs) are a group of noncoding RNAs (ncRNAs) with a closed continuous loop structure, lacking terminal 5 ' caps and 3 ' tails [9]. They are generated in the process of back-splicing and often dynamically expressed among various tissues and cell types [10,11]. Generally, circRNAs regulate gene expression via different modes [12]: (a) Act as miRNA sponges by competing for miRNA binding sites; (b) interact with RNA-binding proteins (RBPs); (c) sequester mRNA translation start sites; (d) encode proteins. Recently, an increasing number of studies have found a regulatory function of circRNAs in several diseases, including cancers, cardiovascular diseases, neurological disorders, diabetes and infection [13-17]. Li et al have found some dysregulated circRNAs in IPF through microarrays [18]. 
However, the function and underlying molecular mechanism of circRNAs involved in IPF are uncertain and incomplete. In the present study, comprehensive bioinformatic analysis were conducted to further provide some critical information for the function of circRNAs in IPF.

\section{Methods}

\section{Identify differentially expressed circRNA profiles in IPF}

We searched in the NCBI (National Center for Biotechnology Information) Gene Expression Omnibus (GEO) database [19] to find the circRNA expression profiles of human IPF. The microarray data GSE102660 including 3 plasma samples from IPF patients and 3 plasma samples from healthy individuals was obtained and differentially expressed circRNAs were identified through R software (version 3.6.1). Limma package was used to find the different expression between control group and IPF group. P-value $<0.05$ and $\mid \log _{2}$ (fold change) $\mid>1$ were considered to be significantly different.

Subsequently, a volcano plot and a heat map were used to display the differential expression of circRNAs between the two groups.

\section{Verify circRNA targeting miRNAs}

The general characteristic of circRNAs was verified via circBase database [20]. circRNAtargeting miRNAs were identified in CSCD database [21]. A schematic diagram of the structure was used to show the functional area of differentially expressed circRNAs, including MREs, RBPs and ORFs.

\section{Construct circRNA-miRNA-mRNA Interaction Networks}

Identification of target genes for circRNAtargeting miRNAs is critical for characterizing the function of circRNAs. In present study, the related target genes

were predicted by integrating miRDB [22], TargetScan [23] and miRTarBase [24] databases. To make our results more convincible, only the target genes predicted by all three databases were selected for further analysis. Finally, the circRNA-miRNA-mRNA interaction network was drawn using Cytoscape software (version 3.7.1).

\section{Analyze Molecular Function And Enriched Pathways For circRNA-targeting Genes}

Molecular function of the circRNA-target genes was further analyzed using GO enrichment. In addition, enriched pathways of circRNA-target genes were identified using KEGG analysis. The GO and KEGG analysis were performed using $\mathrm{R}$ software. The P-value $<0.05$ was considered significant. A bar and a 

genes.

\section{Results}

\section{Identification of differentially expressed circRNA profiles in IPF}

Based on the analysis of GSE102660, differentially expressed circRNAs were identified using R language. It was considered significantly different that P-value $<0.05$ and $\mid \log _{2}$ (fold change) $\mid>1$ compared to control group. As shown in Fig. 1A, a volcano plot visualized the differential expression of circRNAs between the IPF group and control group. Figure 1B revealed the differential expression profiles of circRNAs in the two groups using hierarchical cluster analysis. Finally, 19 differentially expressed circRNAs were identified between the IPF group and control group, of which 6 circRNAs were significantly up-regulated and 13 circRNAs were significantly down-regulated. The details are listed in Table 1. 
Table 1

The differentially expressed circRNAs in idiopathic pulmonary fibrosis

\begin{tabular}{|lllllll|}
\hline CircRNA & $\begin{array}{l}\text { Fold } \\
\text { change }\end{array}$ & P-value & Regulation & $\begin{array}{l}\text { CircRNA } \\
\text { type }\end{array}$ & Chromosome & $\begin{array}{l}\text { Gene } \\
\text { symbol }\end{array}$ \\
\hline hsa_circ_0004099 & 1.253335 & 0.000152 & Up & Exonic & 11 & DENND5A \\
\hline hsa_circ_0008898 & 1.265496 & 0.000179 & Up & Exonic & 10 & OAT \\
\hline hsa_circ_0044226 & 1.421143 & 0.000686 & Up & Exonic & 17 & CDC27 \\
\hline hsa_circ_0007535 & 1.057601 & 0.002525 & Up & Exonic & 18 & ELP2 \\
\hline hsa_circ_0044234 & 1.079494 & 0.007508 & Up & Exonic & 17 & CDC27 \\
\hline hsa_circ_0035796 & 1.168627 & 0.010805 & Up & Exonic & 15 & HERC1 \\
\hline hsa_circ_0029633 & 1.366249 & 0.000090 & Down & Exonic & 13 & ZMYM2 \\
\hline hsa_circ_0001861 & 1.307861 & 0.000407 & Down & Exonic & 9 & GRHPR \\
\hline hsa_circ_0043278 & 2.114709 & 0.000707 & Down & Exonic & 17 & TADA2A \\
\hline hsa_circ_0001556 & 1.003207 & 0.001254 & Down & Intronic & 5 & ERGIC1 \\
\hline hsa_circ_0005465 & 1.167819 & 0.003007 & Down & Exonic & 12 & CLIP1 \\
\hline hsa_circ_0049888 & 1.133704 & 0.005791 & Down & Exonic & 19 & EPS15L1 \\
\hline hsa_circ_0000422 & 1.137055 & 0.018849 & Down & Exonic & 12 & NAP1L1 \\
\hline hsa_circ_0000538 & 1.268418 & 0.019167 & Down & Exonic & 14 & PSMC6 \\
\hline hsa_circ_0000977 & 1.517045 & 0.019465 & Down & Exonic & 2 & NOL10 \\
\hline hsa_circ_0041103 & 1.110617 & 0.032446 & Down & Exonic & 16 & PAPPA \\
\hline hsa_circ_0001497 & 1.071198 & 0.033607 & Down & Exonic & 5 & \\
\hline hsa_circ_0001137 & 1.048250 & 0.046675 & Down & Exonic & 20 & 9 (1) \\
\hline hsa_circ_0088220 & 1.414757 & 0.048550 & Down & Exonic & 9 & \\
\hline circRNA circular RNA & & & & & & \\
\hline
\end{tabular}

\section{Verification Of circRNA-targeting miRNAs}

Since circRNAs interacted with miRNAs via miRNA response elements (MREs) to reduce the miRNA expression and subsequently up-regulated the levels of miRNA target genes, the binding sites of miRNAs for each differentially expressed circRNA were predicted in CSCD database. The top 5 potential miRNA binding sites for the top 10 significantly up-regulated or down-regulated circRNAs were listed in Table 2 . 
Of these, the top 5 potential miRNA binding sites for the most up-regulated circRNA (hsa_circ_0004099) were miR-4633-5p, miR-3671, miR-4755-3p, miR-665 as well as miR-9-3p, and the top 5 potential miRNA binding sites for the most down-regulated circRNA (hsa_circ_0029633) were miR-124-3p, miR-223-5p, miR-3658, miR-486-5p as well as miR-630.

Table 2

Top 5 miRNA binding sites for the top 10 differentially expressed circRNAs

\begin{tabular}{|llllll|}
\hline CircRNA & MRE1 & MRE2 & MRE3 & MRE4 & MRE5 \\
\hline hsa_circ_0004099 & miR-4633-5p & miR-3671 & miR-4755-3p & miR-665 & miR-9-3p \\
\hline hsa_circ_0008898 & miR-1197 & miR-129-5p & miR-140-5p & miR-203-5p & miR-4635 \\
\hline hsa_circ_0044226 & miR-1233-3p & miR-759 & miR-3529-3p & miR-4305 & miR-5700 \\
\hline hsa_circ_0007535 & miR-1972 & miR-203-3p & miR-3158-5p & miR-544a & miR-630 \\
\hline hsa_circ_0044234 & miR-1251-3p & miR-1302 & miR-337-3p & miR-4289 & miR-4425 \\
\hline hsa_circ_0029633 & miR-124-3p & miR-223-5p & miR-3658 & miR-486-5p & miR-630 \\
\hline hsa_circ_0001861 & miR-1306-5p & miR-212-5p & miR-4437 & miR-6837-3p & miR-7150 \\
\hline hsa_circ_0043278 & miR-4659-3p & miR-526-5p & miR-6885-3p & miR-7974 & miR-922 \\
\hline hsa_circ_0001556 & miR-1288-5p & miR-383-5p & miR-4290 & miR-6784-3p & miR-6823-5p \\
\hline hsa_circ_0005465 & miR-5091 & miR-8063 & miR-1290 & miR-3610 & miR-4428 \\
\hline circRNA circular RNA, MRE miRNA & response element, miRNA microRNA & \\
\hline
\end{tabular}

\section{Construction of circRNA-miRNA-mRNA Interaction Networks}

Next, the most up-regulated circRNA (hsa_circ_0004099) and down-regulated circRNA (hsa_circ_0029633) were chosen for further analysis. In circBase database, hsa_circ_0004099 and hsa_circ_0029633 were found located at chromosome 11: 9225206-9229179 and chromosome 13: 20625572-20641530, respectively. Their functional structures including MREs, RBPs and open reading frames (ORFs) were summarized in Fig. 2A and Fig. 3A. Then target genes of the top 5 miRNAs for hsa_circ_0004099 and hsa_circ_002963 were predicted by integrating miRDB, TargetScan and miRTarBase tools. Finally, the top 10 target genes of each circRNAtargeting miRNA predicted by all the three databases were chosen to build circRNA-miRNA-mRNA interaction networks. The results are presented in Fig. 2B and Fig. 3B. 


\section{GO And KEGG Enrichment Analysis For circRNA-targeting Genes}

The most up-regulated hsa_circ_0004099 and down-regulated hsa_circ_0029633 were selected for further investigation by Gene Ontology (GO; geneontology.org) and Kyoto Encyclopedia of Genes and Genomes (KEGG; www.kegg.jp) analysis. For hsa_circ_0004099, the target genes mainly participated in the molecular function of proximal promoter sequence-specific DNA binding, RNA polymerase II proximal promoter sequence-specific DNA binding and core promoter binding $(P<0.05)$, as shown in Fig. 4A and Table 3. KEGG pathways were also identified for the target genes of hsa_circ_0004099. Figure 4B and Table 4 presented that the enriched pathways included hepatitis $B$, measles, kaposi sarcoma-associated herpesvirus infection, p53 signaling pathway, thyroid hormone signaling pathway, cell cycle, and so on ( $P$ $<0.05)$. hsa_circ_0004099targeting genes that participated in cell cycle and p53 signaling pathway were shown in Additional file 1: S1 and Additional file 2: S2. For hsa_circ_0029633, the molecular function of target genes was mainly enriched in cell adhesion molecule binding, cadherin binding, molecular adaptor activity, protein binding, chromatin DNA binding, and so on, as shown in Fig. 5A and Table 5. Figure 5B and Table 6 showed that the enriched pathways for target genes of hsa_circ_0029633 involved non-small cell lung cancer, cellular senescence, focal adhesion, glioma, acute myeloid leukemia, PI3K-Akt signaling pathway, estrogen signaling pathway, prolactin signaling pathway, prolactin signaling pathway, and so on. hsa_circ_0029633targeting genes that participated in ErbB, EGFR tyrosine kinase inhibitor resistance, FOXO, Ras, sphingolipid and PI3K-AKT signaling pathways were shown in Additional file 3: S3-Additional file 8: S8.

Table 3

GO analysis for hsa_circ_0004099targeting genes

\begin{tabular}{|llll|}
\hline ID & Term & $\begin{array}{l}\text { P- } \\
\text { value }\end{array}$ & Genes annotated to the term \\
\hline Molecular function & & \\
\hline G0:0000987 & $\begin{array}{l}\text { proximal promoter sequence-specific } \\
\text { DNA binding }\end{array}$ & $\begin{array}{l}8.51 \mathrm{E}- \\
05\end{array}$ & $\begin{array}{l}\text { NONO| CDK9| HOXA9| HEYLI } \\
\text { SIX4| HIF1A| CREBBP| MYC... }\end{array}$ \\
\hline G0:0000978 & $\begin{array}{l}\text { RNA polymerase II proximal promoter } \\
\text { sequence-specific DNA binding }\end{array}$ & 0.0001 & $\begin{array}{l}\text { NONO| CDK9| MYC| HOXA9 } \\
\text { ETS2| SIX4| NR3C1| SOX4... }\end{array}$ \\
\hline G0:0001047 & core promoter binding & 0.0413 & $\begin{array}{l}\text { MYC| POU2F1| KLF10| H3F3B| } \\
\text { NR3C1| BAZ2A }\end{array}$ \\
\hline G0 gene ontology & & \\
\hline
\end{tabular}


Table 4

KEGG enrichment analysis for hsa_circ_0004099targeting genes

\begin{tabular}{|c|c|c|c|c|c|}
\hline Term & ID & $\begin{array}{l}\text { Sample } \\
\text { number }\end{array}$ & $\begin{array}{l}\text { Background } \\
\text { number }\end{array}$ & P-value & Genes \\
\hline Hepatitis B & hsa05161 & 14 & 165 & 0.001494 & $\begin{array}{l}\text { CYCS| MYC| } \\
\text { MAP3K7| } \\
\text { STAT2| } \\
\text { DDX3X| } \\
\text { IFNAR1... }\end{array}$ \\
\hline Measles & hsa05162 & 12 & 165 & 0.002412 & $\begin{array}{l}\text { CYCS| MAVS| } \\
\text { STAT5B| } \\
\text { APAF1| } \\
\text { CCND1| } \\
\text { CDK6... }\end{array}$ \\
\hline $\begin{array}{l}\text { Kaposi sarcoma-associated } \\
\text { herpesvirus infection }\end{array}$ & hsa05167 & 14 & 165 & 0.002412 & $\begin{array}{l}\text { CCR5| CYCS | } \\
\text { CCND1| MYC| } \\
\text { ZFP36| } \\
\text { STAT2... }\end{array}$ \\
\hline p53 signaling pathway & hsa04115 & 8 & 165 & 0.006778 & $\begin{array}{l}\text { MDM2| } \\
\text { CYCS| } \\
\text { CCND1| } \\
\text { PMAIP1| } \\
\text { RRM2| } \\
\text { APAF1... }\end{array}$ \\
\hline $\begin{array}{l}\text { Thyroid hormone signaling } \\
\text { pathway }\end{array}$ & hsa04919 & 10 & 165 & 0.010790 & $\begin{array}{l}\text { ACTG1| } \\
\text { MDM2| } \\
\text { NOTCH2| } \\
\text { CCND1| MYC| } \\
\text { PLCB2... }\end{array}$ \\
\hline Epstein-Barr virus infection & hsa05169 & 13 & 165 & 0.010559 & $\begin{array}{l}\text { CDK6| } \\
\text { CCND2| } \\
\text { APAF1| } \\
\text { MAVS| } \\
\text { STAT3| } \\
\text { IFNAR1... }\end{array}$ \\
\hline Hepatitis C & hsa05160 & 11 & 165 & 0.021266 & $\begin{array}{l}\text { APAF1| } \\
\text { MAVS| IFIT1| } \\
\text { TBK1| } \\
\text { STAT3| } \\
\text { IFNAR1... }\end{array}$ \\
\hline $\begin{array}{l}\text { Human cytomegalovirus } \\
\text { infection }\end{array}$ & hsa05163 & 13 & 165 & 0.021266 & $\begin{array}{l}\text { ADCY7| } \\
\text { CDK6| } \\
\text { VEGFAI } \\
\text { WNT1| } \\
\text { PLCB2| } \\
\text { TBK1... }\end{array}$ \\
\hline
\end{tabular}

KEGG Kyoto encyclopedia of genes and genome 


\begin{tabular}{|c|c|c|c|c|c|}
\hline Term & ID & $\begin{array}{l}\text { Sample } \\
\text { number }\end{array}$ & $\begin{array}{l}\text { Background } \\
\text { number }\end{array}$ & P-value & Genes \\
\hline Influenza A & hsa05164 & 11 & 165 & 0.021266 & $\begin{array}{l}\text { TBK1| } \\
\text { IFNAR1| } \\
\text { DNAJC3| } \\
\text { CREBBP| } \\
\text { KPNA6... }\end{array}$ \\
\hline Cell cycle & hsa04110 & 9 & 165 & 0.025571 & $\begin{array}{l}\text { MDM2| } \\
\text { BUB3| } \\
\text { CCND1| MYC| } \\
\text { MAD2L1| } \\
\text { CCND2... }\end{array}$ \\
\hline
\end{tabular}


GO analysis for hsa_circ_0029633targeting genes

\begin{tabular}{|c|c|c|c|}
\hline ID & Term & $\begin{array}{l}\mathrm{P} \text { - } \\
\text { value }\end{array}$ & Genes annotated to the term \\
\hline \multicolumn{4}{|c|}{ Molecular function } \\
\hline G0:0050839 & cell adhesion molecule binding & $\begin{array}{l}9.58 \mathrm{E}- \\
07\end{array}$ & $\begin{array}{l}\text { CD226| DSG2| MPRIP| ITGB1| } \\
\text { HMGB1| EIF5| BZW1| PCMT1... }\end{array}$ \\
\hline GO:0045296 & cadherin binding & $\begin{array}{l}4.24 \mathrm{E}- \\
06\end{array}$ & $\begin{array}{l}\text { MPRIP| ITGB1| EIF5| BZW1| } \\
\text { PCMT1| HSPA1A| RAB1A... }\end{array}$ \\
\hline G0:0060090 & molecular adaptor activity & $\begin{array}{l}1.35 \mathrm{E}- \\
05\end{array}$ & $\begin{array}{l}\text { CAV1| NCK2| SH2B3| DISC1| } \\
\text { TJP2| ITSN2| PAG1| BICD2... }\end{array}$ \\
\hline GO:0030674 & protein binding & $\begin{array}{l}5.42 \mathrm{E}- \\
05\end{array}$ & $\begin{array}{l}\text { CAV1| NCK2| SH2B3| TJP2| } \\
\text { ITSN2| LDLRAP1| BICD2... }\end{array}$ \\
\hline GO:0031490 & chromatin DNA binding & 0.0001 & $\begin{array}{l}\text { STAT3| H1FO| H3F3B| NKAPI } \\
\text { HMGN2| BCL6| RXRA| RELA... }\end{array}$ \\
\hline GO:0035591 & signaling adaptor activity & 0.0001 & $\begin{array}{l}\text { NCK2| SH2B3| ITSN2| LDLRAP1| } \\
\text { PAG1| PTPN11| GRB2... }\end{array}$ \\
\hline G0:0019887 & protein kinase regulator activity & 0.0001 & $\begin{array}{l}\text { PRKAG1| PARP16| DAZAP2| } \\
\text { YWHAG| TRIB3| TOM1L1... }\end{array}$ \\
\hline G0:0004721 & phosphoprotein phosphatase activity & 0.0001 & $\begin{array}{l}\text { PTPRE| PTPN4| PTPRJ| } \\
\text { PPP1R3B| PTPN9| PTPN14| } \\
\text { PTPRB... }\end{array}$ \\
\hline GO:0000978 & $\begin{array}{l}\text { RNA polymerase II proximal promoter } \\
\text { sequence-specific DNA binding }\end{array}$ & 0.0002 & $\begin{array}{l}\text { SMAD5| NFIA| SIX4| SP1| } \\
\text { PRRX1| HOXA9| SOX4| RXRA... }\end{array}$ \\
\hline GO:0000987 & $\begin{array}{l}\text { proximal promoter sequence-specific } \\
\text { DNA binding }\end{array}$ & 0.0002 & $\begin{array}{l}\text { SMAD5| NFIA| SIX4| HOXA9| } \\
\text { SOX4| LHX2| ZNF516| RARA... }\end{array}$ \\
\hline GO:0004725 & protein tyrosine phosphatase activity & 0.0004 & $\begin{array}{l}\text { PTPRE| PTPN4| PTPRJ| PTPN9| } \\
\text { PTPN14| PTPRB| DUSP19... }\end{array}$ \\
\hline G0:0019207 & kinase regulator activity & 0.0005 & $\begin{array}{l}\text { PRKAG1| PARP16| DAZAP2| } \\
\text { YWHAG| TRIB3| TOM1L1... }\end{array}$ \\
\hline GO:0005070 & $\mathrm{SH} 3 / \mathrm{SH} 2$ adaptor activity & 0.0005 & $\begin{array}{l}\text { NCK2| SH2B3| ITSN2| PAG1| } \\
\text { PTPN11| GRB2| LASP1 ... }\end{array}$ \\
\hline G0:0016791 & phosphatase activity & 0.0005 & $\begin{array}{l}\text { NUDT16| PTPRE| PTPN4| } \\
\text { PTPRJ| CTDSP1| PPP1R3B| } \\
\text { PPP2R... }\end{array}$ \\
\hline
\end{tabular}


Table 5

Continued

\begin{tabular}{|c|c|c|c|}
\hline ID & Term & $\begin{array}{l}\text { P- } \\
\text { value }\end{array}$ & Genes annotated to the term \\
\hline \multicolumn{4}{|c|}{ Molecular function } \\
\hline G0:0030295 & $\begin{array}{l}\text { protein kinase activator } \\
\text { activity }\end{array}$ & 0.0007 & $\begin{array}{l}\text { PARP16| DAZAP2| TOM1L1| CCNB1| } \\
\text { IQGAP1| DDX3X... }\end{array}$ \\
\hline GO:0005543 & phospholipid binding & 0.0008 & $\begin{array}{l}\text { SH3PXD| ARAP2| JAG1| OSBP| GOLPH3| } \\
\text { PIK3C2A| HMGB1... }\end{array}$ \\
\hline G0:0008093 & cytoskeletal adaptor activity & 0.0009 & NCK2| BICD2| SDCBP| ABI2 \\
\hline G0:0045309 & $\begin{array}{l}\text { protein phosphorylated amino } \\
\text { acid binding }\end{array}$ & 0.0009 & $\begin{array}{l}\text { NCK2| POU2F1| KLF10| H3F3B| NR3C1| } \\
\text { BAZ2A }\end{array}$ \\
\hline GO:0001228 & $\begin{array}{l}\text { DNA-binding transcription } \\
\text { activator activity }\end{array}$ & 0.0009 & $\begin{array}{l}\text { LDLRAP1| NCK2| ABL2| BTRC| PTPN11| } \\
\text { GRB2| SHC1 }\end{array}$ \\
\hline G0:0031267 & small GTPase binding & 0.0010 & $\begin{array}{l}\text { NFIA| SIX4| FOXC1| SP1| EGR1| NR4A1| } \\
\text { SOX4| CREBRF... }\end{array}$ \\
\hline G0:0019209 & kinase activator activity & 0.0011 & $\begin{array}{l}\text { PARP16| DAZAP2| TOM1L1| CCNB1| } \\
\text { IQGAP1| DDX3X... }\end{array}$ \\
\hline GO:0070273 & $\begin{array}{l}\text { phosphatidylinositol-4- } \\
\text { phosphate binding }\end{array}$ & 0.0014 & $\begin{array}{l}\text { SH3PXD2A| OSBPL8| GOLPH3| OSBP| } \\
\text { ARFIP1 }\end{array}$ \\
\hline G0:0017016 & Ras GTPase binding & 0.0015 & $\begin{array}{l}\text { SOS2 | CAV1| DENND6A| RNF41| ROCK1| } \\
\text { DOCK3| SPATA13... }\end{array}$ \\
\hline \multicolumn{4}{|c|}{ GO gene ontology } \\
\hline
\end{tabular}


Table 6

KEGG enrichment analysis for hsa_circ_0029633targeting genes

\begin{tabular}{|c|c|c|c|c|c|}
\hline Term & ID & $\begin{array}{l}\text { Sample } \\
\text { number }\end{array}$ & $\begin{array}{l}\text { Background } \\
\text { number }\end{array}$ & $\begin{array}{l}\mathrm{P} \text { - } \\
\text { value }\end{array}$ & Genes \\
\hline non-small cell lung cancer & hsa05223 & 12 & 308 & 0.0018 & $\begin{array}{l}\text { SOS2| CCND1| } \\
\text { STAT3| AKT3| RXRA| } \\
\text { RASSF5| SOS1... }\end{array}$ \\
\hline cellular senescence & hsa04218 & 19 & 308 & 0.0018 & $\begin{array}{l}\text { CCND1| ZFP36L1| } \\
\text { AKT3| MAPK14| } \\
\text { RRAS| SERPINE1 ... }\end{array}$ \\
\hline focal adhesion & hsa04510 & 21 & 308 & 0.0027 & $\begin{array}{l}\text { SOS2| CCND1| } \\
\text { CAV1| ARHGAP5| } \\
\text { ROCK1| AKT3... }\end{array}$ \\
\hline glioma & hsa05214 & 11 & 308 & 0.0095 & $\begin{array}{l}\text { SOS2| CCND1| } \\
\text { PDGFRA| PTEN| } \\
\text { PRKCA| CDK4... }\end{array}$ \\
\hline acute myeloid leukemia & hsa05221 & 10 & 308 & 0.0112 & $\begin{array}{l}\text { RELA| GRB2| CEBPA| } \\
\text { RUNX1| SOS1| } \\
\text { RARA| AKT3... }\end{array}$ \\
\hline $\begin{array}{l}\text { PI3K-Akt signaling } \\
\text { pathway }\end{array}$ & hsa04151 & 28 & 308 & 0.0112 & $\begin{array}{l}\text { PPP2| PDGFRA| } \\
\text { SOS1| LAMC1| } \\
\text { CREB3L2| RXRA... }\end{array}$ \\
\hline $\begin{array}{l}\text { estrogen signaling } \\
\text { pathway }\end{array}$ & hsa04915 & 15 & 308 & 0.0112 & $\begin{array}{l}\text { R2A| PTEN| PRKCA| } \\
\text { CDK4| GRB2| SGK1| } \\
\text { RELA... }\end{array}$ \\
\hline $\begin{array}{l}\text { prolactin signaling } \\
\text { pathway }\end{array}$ & $\begin{array}{l}\text { hsa } \\
04917\end{array}$ & 10 & 308 & 0.0112 & $\begin{array}{l}\text { CCND2| SGK1| } \\
\text { GRB2| PTEN| } \\
\text { CCNB1| } \\
\text { BCL6|GRM1... }\end{array}$ \\
\hline proteoglycans in cancer & hsa05205 & 19 & 308 & 0.0112 & $\begin{array}{l}\text { PPP1CB| IQGAP1| } \\
\text { SMAD2| PRKCA| } \\
\text { RRAS| MAPK14... }\end{array}$ \\
\hline relaxin signaling pathway & hsa04926 & 14 & 308 & 0.0130 & $\begin{array}{l}\text { COL4A1| RELA| } \\
\text { SMAD2| PRKCA| } \\
\text { CREB3L2| GNG10... }\end{array}$ \\
\hline FOXO signaling pathway & hsa04068 & 14 & 308 & 0.0138 & $\begin{array}{l}\text { CCND2| SGK1| } \\
\text { GRB2| PTEN| } \\
\text { CCNB1| BCL6| } \\
\text { GRM1... }\end{array}$ \\
\hline $\begin{array}{l}\text { regulation of actin } \\
\text { cytoskeleton }\end{array}$ & hsa04810 & 19 & 308 & 0.0143 & $\begin{array}{l}\text { PAK2| ABI2| } \\
\text { PPP1CB| IQGAP1| } \\
\text { WASF2| MYH9| } \\
\text { GSN... }\end{array}$ \\
\hline
\end{tabular}




\begin{tabular}{|c|c|c|c|c|c|}
\hline Term & ID & $\begin{array}{l}\text { Sample } \\
\text { number }\end{array}$ & $\begin{array}{l}\text { Background } \\
\text { number }\end{array}$ & $\begin{array}{l}\mathrm{P} \text { - } \\
\text { value }\end{array}$ & Genes \\
\hline chronic myeloid leukemia & hsa05220 & 10 & 308 & 0.0143 & $\begin{array}{l}\text { SHC1| RELA| GRB2| } \\
\text { PTPN11| CDK4| } \\
\text { RUNX1| AKT3... }\end{array}$ \\
\hline apelin signaling pathway & hsa04371 & 14 & 308 & 0.0156 & $\begin{array}{l}\text { SPHK1| RYR3| } \\
\text { GNAI3| SMAD2| } \\
\text { GNG10| SERPINE1... }\end{array}$ \\
\hline $\begin{array}{l}\text { EGFR tyrosine kinase } \\
\text { inhibitor resistance }\end{array}$ & hsa01521 & 10 & 308 & 0.0156 & $\begin{array}{l}\text { SHC1| TGFA| GRB2| } \\
\text { PRKCAI PTEN| } \\
\text { PDGFRA| SOS1... }\end{array}$ \\
\hline Hippo signaling pathway & hsa04390 & 15 & 308 & 0.0156 & $\begin{array}{l}\text { RASSF1| FRMD6| } \\
\text { SNAI2| CCND2| } \\
\text { YAP1| BMP6... }\end{array}$ \\
\hline insulin resistance & hsa04931 & 12 & 308 & 0.0116 & $\begin{array}{l}\text { RELA| PTPN11| } \\
\text { PPP1CB| PTEN| } \\
\text { MLXIP| CREB3L2... }\end{array}$ \\
\hline $\begin{array}{l}\text { other types of O-glycan } \\
\text { biosynthesis }\end{array}$ & hsa00514 & 5 & 308 & 0.0201 & $\begin{array}{l}\text { PLOD3| POFUT1| } \\
\text { B4GALT1| GXYLT1| } \\
\text { POGLUT1... }\end{array}$ \\
\hline ErbB signaling pathway & hsa04012 & 10 & 308 & 0.0228 & $\begin{array}{l}\text { PAK2| SHC1| TGFA| } \\
\text { GRB2| ABL2| PRKCA| } \\
\text { AKT3... }\end{array}$ \\
\hline
\end{tabular}


Table 6

Continued

\begin{tabular}{|c|c|c|c|c|c|}
\hline Term & ID & $\begin{array}{l}\text { Sample } \\
\text { number }\end{array}$ & $\begin{array}{l}\text { Background } \\
\text { number }\end{array}$ & $\begin{array}{l}\mathrm{P}- \\
\text { value }\end{array}$ & Genes \\
\hline $\begin{array}{l}\text { AGE-RAGE signaling pathway in } \\
\text { diabetic complications }\end{array}$ & hsa04933 & 11 & 308 & 0.0228 & $\begin{array}{l}\text { COL4A1| } \\
\text { RELAI CDK4| } \\
\text { SMAD2| } \\
\text { PRKCA| } \\
\text { SERPINE1... }\end{array}$ \\
\hline Ras signaling pathway & hsa04014 & 19 & 308 & 0.0228 & $\begin{array}{l}\text { PAK2| SHC1| } \\
\text { RASSF1| } \\
\text { TGFA| RELA| } \\
\text { GRB2| } \\
\text { PTPN11... }\end{array}$ \\
\hline sphingolipid signaling pathway & hsa04071 & 12 & 308 & 0.0280 & $\begin{array}{l}\text { ROCK1| AKT3 } \\
\text { |MAPK14| } \\
\text { GNAI2| } \\
\text { SGMS1| } \\
\text { PPP2R2A... }\end{array}$ \\
\hline $\begin{array}{l}\text { transcriptional misregulation in } \\
\text { cancer }\end{array}$ & hsa05202 & 10 & 308 & 0.0288 & $\begin{array}{l}\text { CCND2| RELA } \\
\text { ELK4| KLF3| } \\
\text { CDK9| CEBPA } \\
\text { RUNX1... }\end{array}$ \\
\hline hepatitis C & hsa05160 & 14 & 308 & 0.0234 & $\begin{array}{l}\text { CLDN1| RELA } \\
\text { GRB2| CDK4| } \\
\text { PPP2R2A| } \\
\text { SOS1| RXRA.. }\end{array}$ \\
\hline $\begin{array}{l}\text { human cytomegalovirus } \\
\text { infection }\end{array}$ & hsa05163 & 18 & 308 & 0.0313 & $\begin{array}{l}\text { GNAI3| RELA| } \\
\text { GRB2| CDK4| } \\
\text { PRKCA| } \\
\text { PDGFRA... }\end{array}$ \\
\hline small cell lung cancer & hsa05222 & 10 & 308 & 0.0313 & $\begin{array}{l}\text { COL4A1| } \\
\text { RELA| CDK4| } \\
\text { PTEN| } \\
\text { LAMC1| } \\
\text { RXRA| AKT3... }\end{array}$ \\
\hline $\begin{array}{l}\text { leukocyte transendothelial } \\
\text { migration }\end{array}$ & hsa04670 & 11 & 308 & 0.0386 & $\begin{array}{l}\text { ARHGAP5| } \\
\text { ROCK1| } \\
\text { ITGB1| } \\
\text { MAPK14| } \\
\text { GNAI2| } \\
\text { CLDN1... }\end{array}$ \\
\hline
\end{tabular}

KEGG Kyoto encyclopedia of genes and genome 


\begin{tabular}{|c|c|c|c|c|c|}
\hline Term & ID & $\begin{array}{l}\text { Sample } \\
\text { number }\end{array}$ & $\begin{array}{l}\text { Background } \\
\text { number }\end{array}$ & $\begin{array}{l}\text { P- } \\
\text { value }\end{array}$ & Genes \\
\hline toxoplasmosis & hsa05145 & 11 & 308 & 0.0386 & $\begin{array}{l}\text { GNAI2| } \\
\text { LAMC1| PPIF| } \\
\text { RELA| GNAI3| } \\
\text { TYK2| AKT3... }\end{array}$ \\
\hline JAK-STAT signaling pathway & hsa04630 & 14 & 308 & 0.0386 & $\begin{array}{l}\text { STAT3| } \\
\text { IFNAR2| } \\
\text { MCL1| } \\
\text { PDGFRA| } \\
\text { GRB2| } \\
\text { CCND2... }\end{array}$ \\
\hline shigellosis & hsa05131 & 8 & 308 & 0.0386 & $\begin{array}{l}\text { RELA| BTRC| } \\
\text { WASF2| } \\
\text { RHOG| } \\
\text { MAPK14| } \\
\text { ARPC1B... }\end{array}$ \\
\hline prostate cancer & hsa05215 & 10 & 308 & 0.0386 & $\begin{array}{l}\text { TGFA| RELA| } \\
\text { GRB2| PTEN| } \\
\text { PDGFRA| } \\
\text { CREB3L2... }\end{array}$ \\
\hline endocrine resistance & hsa01522 & 10 & 308 & 0.0393 & $\begin{array}{l}\text { SHC1| GRB2| } \\
\text { CDK4| SOS1| } \\
\text { SP1| } \\
\text { MAPK14| } \\
\text { JAG1... }\end{array}$ \\
\hline bladder cancer & hsa05219 & 6 & 308 & 0.0393 & $\begin{array}{l}\text { CCND1| } \\
\text { RPS6KA5| } \\
\text { THBS1| } \\
\text { DAPK1| } \\
\text { CDK4| } \\
\text { RASSF1... }\end{array}$ \\
\hline dopaminergic synapse & hsa04728 & 12 & 308 & 0.0400 & $\begin{array}{l}\text { GNAI3| GRIA2| } \\
\text { PPP1CB| } \\
\text { CLOCK| } \\
\text { PRKCA| } \\
\text { PPP2R2A... }\end{array}$ \\
\hline
\end{tabular}

\section{Discussion}

IPF is a progressive and ultimately fatal interstitial lung disease, whose available therapies are limited [2, 25]. Deeply to explore the pathogenesis and further to find new therapeutic options for IPF are a clear and urgent need. circRNAs are a class of the non-coding RNA family and play an important role in the development of multiple lung diseases [26-28]. Recently, studies have detect circRNAs with abnormal expression in IPF using a high-throughput microarray assay and found that several circRNAs may be 
potential biomarkers and promising molecular targets for the diagnosis and treatment of IPF [18, 29]. However, the function and underlying molecular mechanism of circRNAs contributing to the development of IPF remain largely uncertain and incomplete.

In this study, 6 significantly up-regulated and 13 significantly down-regulated circRNAs were identified based on the analysis of GSE102660 through R software. Of these, the most up-regulated circRNA (hsa_circ_0004099) and down-regulated circRNA (hsa_circ_0029633) were chosen for further analysis. The top 5 potential miRNA binding sites for hsa_circ_0004099 were miR-4633-5p, miR-3671, miR-4755-3p, miR-665 as well as miR-9-3p, and the top 5 potential miRNA binding sites for hsa_circ_0029633 were miR124-3p, miR-223-5p, miR-3658, miR-486-5p as well as miR-630. Next, target genes of the top 5 miRNAs for hsa_circ_0004099 and hsa_circ_0029633 were predicted and the circRNA-miRNA-mRNA interaction networks were constructed. Finally, GO analysis showed that target genes of hsa_circ_0004099 were enriched in proximal promoter sequence-specific DNA binding, RNA polymerase II proximal promoter sequence-specific DNA binding as well as core promoter binding, and target genes of hsa_circ_0029633 were enriched in many biological processes, such as cell adhesion molecule binding, molecular adaptor activity, chromatin DNA binding, signaling adaptor activity as well as phosphoprotein phosphatase activity, and so on. In KEGG pathway analysis, the target genes of hsa_circ_0004099 were mainly located in p53 signaling pathway, thyroid hormone signaling pathway, Epstein-Barr virus infection and cell cycle signaling pathways; while the target genes of hsa_circ_0029633 were mainly located in focal adhesion signaling pathway, PI3K-Akt signaling pathway, FOXO signaling pathway, EGFR tyrosine kinase inhibitor resistance signaling pathway, Hippo signaling pathway, ErbB signaling pathway as well as Ras signaling pathway, and so on. These results indicated that hsa_circ_0004099 and hsa_circ_0029633 might regulate crucial biological processes during the development of IPF.

Several studies have shown that dysregulation of miR-4633 and miR-9

is involved in the pathogenesis of IPF [30,31], and increased expression of IGFBP5 and ITGB1 plays a vital role in the development of IPF [32,33]. Our present results suggested that up-regulated hsa_circ_0004099 might promote the development of IPF by decreasing the expression of miR-4633 or miR-9, and further increasing the expression of IGFBP5 or ITGB1, respectively. MAP3K7, TBK1 and ETS2 have been proved crucial factors in IPF progression [34-36], and these genes were predicted as downstream targets of miR-3671, which was negatively modulated by hsa_circ_0004099 in our analysis, suggesting that over-expression of hsa_circ_0004099 induced pulmonary fibrosis via reduction of miR3671 and consequent increase of MAP3K7, TBK1 or ETS2.

In our analysis, many genes such as SMAD5, CAV1, JAG1, ROCK1 and STAT3 were positively predicted as downstream targets of miR-124, which was regarded as a potential miRNA binding site of hsa_circ_0029633. Previous studies have demonstrated that miR-124 plays a key role in multiple diseases including IPF by targeting SMAD5, CAV1, JAG1, ROCK1 or STAT3 [37-42], which is consistent with our findings. Previous studies have also shown that FOXC1 and HSPA1A are direct target genes of miR-223 [43,44], and these genes contribute to the pathogenesis of IPF via activating various signaling 
pathways. Our present results suggested that down-regulated hsa_circ_0029633 might promote the development of IPF by increasing the expression of miR-223, and further decreasing the expression of FOXC1 and HSPA1A. In addition, we found that hsa_circ_0029633/ miR-486-5p and hsa_circ_0029633/ miR-630 signaling axes were also involved in the development of IPF via targeting CADM1 and OLFM4, as well as PDGFRA and YAP1, respectively.

Several published studies have demonstrated that up-regulation of miR-486-5p and miR-630 contributes to IPF progression $[45,46]$ and CADM1, OLFM4, PDGFRA as well as YAP1 genes play a crucial role in the pathogenesis of IPF [47-50].

Some limitations should be addressed when interpreting the results: (a) The differentially expressed circRNAs were identified only based on microarray data GSE102660 and they still needed further verification in animal and human lungs; (b)

the function of the differentially expressed circRNAs in IPF was predicted only using bioinformatic analysis, and there was no further study in vivo or in vitro to demonstrate the roles of candidate circRNAs in the pathogenesis of IPF; (c) generally, circRNAs regulate gene expression via several modes [12], such as acting as miRNA sponges, interacting with RBPs, sequestering mRNA translation start sites and encoding proteins, while the current study was performed only according to the miRNA sponge function of circRNAs.

\section{Conclusion}

6 significantly up-regulated and 13 significantly down-regulated circRNAs were identified involved in the pathogenesis of IPF in present study. The binding sites of miRNAs for each differentially expressed circRNA were also predicted and circRNA-miRNA-mRNA networks were constructed for the most upregulated hsa_circ_0004099 and down-regulated hsa_circ_0029633. In addition, GO and KEGG enrichment analysis revealed the molecular function and enriched pathways of the target genes of circRNAs in IPF. These findings suggest that candidate circRNAs might serve an important role in the pathogenesis of IPF. Therefore, these circRNAs might be potential biomarkers for diagnosis and promising targets for treatment of IPF, which still need further verification in vivo and in vitro.

\section{Abbreviations}

IPF: idiopathic pulmonary fibrosis; ILD: interstitial lung disease; circRNAs: circular RNAs; ncRNAs: noncoding RNAs; RBPs: RNA-binding proteins; MREs: miRNA response elements; ORFs: open reading frames; NCBI: National Center for Biotechnology Information; GEO: Gene Expression Omnibus.

\section{Additional Files}

Additional file 1: S1. hsa_circ_0004099-targeting genes participated in cell cycle signaling pathway. Red squares represent the hsa_circ_0004099-targeting genes 
Additional file 2: S2. hsa_circ_0004099-targeting genes participated in p53 signaling pathway. Red squares represent the hsa_circ_0004099-targeting genes

Additional file 3: S3. hsa_circ_0029633-targeting genes participated in ErbB signaling pathway. Red squares represent the hsa_circ_0029633-targeting genes

Additional file 4: S4. hsa_circ_0029633-targeting genes participated in EGFR tyrosine kinase inhibitor resistance signaling pathway. Red squares represent the hsa_circ_0029633-targeting genes

Additional file 5: S5. hsa_circ_0029633-targeting genes participated in FOXO signaling pathway. Red squares represent the hsa_circ_0029633-targeting genes

Additional file 6: S6. hsa_circ_0029633-targeting genes participated in Ras signaling pathway. Red squares represent the hsa_circ_0029633-targeting genes

Additional file 7: S7. hsa_circ_0029633-targeting genes participated in sphingolipid signaling pathway. Red squares represent the hsa_circ_0029633-targeting genes

Additional file 8: S8. hsa_circ_0029633-targeting genes participated in PI3K-AKT signaling pathway. Red squares represent the hsa_circ_0029633-targeting genes

\section{Declarations}

\section{Authors' contributions}

Fangwei Li and Yixin Wan: designed the study. Hong Wang and Hongyan Tao: analyzed and interpreted the data. Fanqi Wu and Dan Wang: organized the results. Fangwei Li: wrote the manuscript.

\section{Author details}

Department of Respiratory Medicine, Lanzhou University Second Hospital, Lanzhou 730030, China.

\section{Acknowledgents}

The authors gratefully acknowledge contributions from R software, NCBI-GEO database, circBase database, CSCD database, miRDB database, TargetScan database, miRTarBase, Cytoscape software, GO database and KEGG database.

\section{Competing interests}

The authors declare that they have no competing interests.

\section{Availability of data and materials}


We searched in the NCBI (National Center for Biotechnology Information) Gene Expression Omnibus (GEO) database (https://www.ncbi.nlm.nih.gov/geo/) to find the circRNA expression profiles of human IPF. The general characteristic of circRNAs was verified via circBase database (http://www.circbase.org). circRNA-targeting miRNAs were identified in CSCD database (http://gb.whu.edu.cn/CSCD). The target genes of related miRNAs were predicted by integrating miRDB (http://www.mirdb.org/), TargetScan (http://www.targetscan.org/) and miRTarBase (http://mirtarbase.mbc.nctu.edu.tw/php/index.php) databases.

\section{Consent for publication}

Not applicable.

\section{Ethics approval and consent to participate}

Not applicable.

\section{Funding}

This work was supported by Chinese National Science Foundation (No. 81960014) and Cuiying Scientific and Technological Innovation Program of Lanzhou University Second Hospital (No. CY2018-QN12).

\section{References}

1. Pleasants R, Tighe RM. Management of idiopathic pulmonary fibrosis. Ann Pharmacother. 2019; 53(12):1238-1248.

2. Richeldi L, Collard HR, Jones MG. Idiopathic pulmonary fibrosis. Lancet. 2017;389(10082):1941-52.

3. Doubkova M, Svancara J, Svoboda M, Sterclova M, Bartos V, Plackova M, Lacina L, Zurkova M, Binkova I, Bittenglova R, et al. EMPIRE Registry, Czech Part: Impact of demographics, pulmonary function and HRCT on survival and clinical course in idiopathic pulmonary fibrosis. Clin Respir J. 2018;12(4):1526-35.

4. Glaspole IN, Chapman SA, Cooper WA, Ellis SJ, Goh NS, Hopkins PM, Macansh S, Mahar A, Moodley YP, Paul E, et al. Health-related quality of life in idiopathic pulmonary fibrosis: Data from the Australian IPF Registry. Respirology. 2017;22(5):950-6.

5. Jo HE, Glaspole I, Moodley Y, Chapman S, Ellis S, Goh N, Hopkins P, Keir G, Mahar A, Cooper W, et al. Disease progression in idiopathic pulmonary fibrosis with mild physiological impairment: analysis from the Australian IPF registry. BMC Pulm Med. 2018;18(1):19.

6. Raghu G, Remy-Jardin M, Myers JL, Richeldi L, Ryerson CJ, Lederer DJ, Behr J, Cottin V, Danoff SK, Morell F, et al. Diagnosis of idiopathic pulmonary fibrosis. An Official ATS/ERS/JRS/ALAT Clinical Practice Guideline. Am J Respir Crit Care Med. 2018;198(5):e44-e68.

7. Raghu G, Collard HR, Egan JJ, Martinez FJ, Behr J, Brown KK, Colby TV, Cordier JF, Flaherty KR, Lasky JA, et al. An official ATS/ERS/JRS/ALAT statement: idiopathic pulmonary fibrosis: evidence-based 
guidelines for diagnosis and management. Am J Respir Crit Care Med. 2011;183(6):788-824.

8. Kolilekas L, Papiris S, Bouros D. Existing and emerging treatments for idiopathic pulmonary fibrosis. Expert Rev Respir Med. 2019;13(3):229-39.

9. Chen LL, Yang L. Regulation of circRNA biogenesis. RNA Biol. 2015;12(4):381-8.

10. Du WW, Yang W, Liu E, Yang Z, Dhaliwal P, Yang BB. Foxo3 circular RNA retards cell cycle progression via forming ternary complexes with p21 and CDK2. Nucleic Acids Res. 2016;44(6):2846-58.

11. Barrett SP, Salzman J. Circular RNAs: analysis, expression and potential functions. Development. 2016;143(11):1838-47.

12. Han B, Chao J, Yao H. Circular RNA and its mechanisms in disease: From the bench to the clinic. Pharmacol Ther. 2018;187:31-44.

13. Kristensen LS, Hansen TB, Veno MT, Kjems J. Circular RNAs in cancer: opportunities and challenges in the field. Oncogene. 2018;37(5):555-65.

14. Li M, Ding W, Sun T, Tariq MA, Xu T, Li P, Wang J. Biogenesis of circular RNAs and their roles in cardiovascular development and pathology. FEBS J. 2018;285(2):220-32.

15. Floris G, Zhang L, Follesa P, Sun T. Regulatory role of circular RNAs and neurological disorders. Mol Neurobiol. 2017;54(7):5156-65.

16. Jiang G, Ma Y, An T, Pan Y, Mo F, Zhao D, Liu Y, Miao JN, Gu YJ, Wang Y, et al. Relationships of circular RNA with diabetes and depression. Sci Rep. 2017;7(1):7285.

17. Li X, Liu CX, Xue W, Zhang Y, Jiang S, Yin QF, Wei J, Yao RW, Yang L, Chen LL. Coordinated circRNA biogenesis and function with NF90/NF110 in viral infection. Mol Cell. 2017;67(2):214-27 e7.

18. Li R, Wang Y, Song X, Sun W, Zhang J, Liu Y, Li H, Meng C, Zhang J, Zheng Q, et al. Potential regulatory role of circular RNA in idiopathic pulmonary fibrosis. Int J Mol Med. 2018;42(6):3256-68.

19. 19. NCBI GEO database. https://www.ncbi.nlm.nih.gov/geo/. Accessed 20 October 2019.

20. 20. circBase databa http://www.circbase.org. Accessed 21 October 2019.

21. CSCD database. http://gb.whu.edu.cn/CSCD. Accessed 21 October 2019.

22. miRDB. http://www.mirdb.org/. Accessed 24 October 2019.

23. TargetScan. http://www.ta rgetscan.org/. Accessed 24 October 2019.

24. miRTarBase. http://mirtarbase.mbc.nctu.edu.tw/php/index.php. Accessed 24 October 2019.

25. Collard HR, Ryerson CJ, Corte TJ, Jenkins G, Kondoh Y, Lederer DJ, Lee JS, Maher TM, Wells AU, Antoniou KM, et al. Acute exacerbation of idiopathic pulmonary fibrosis. An international working group report. Am J Respir Crit Care Med. 2016;194(3):265-75.

26. Yao JT, Zhao SH, Liu QP, Lv MQ, Zhou DX, Liao ZJ, Nan KJ. Over-expression of CircRNA_100876 in non-small cell lung cancer and its prognostic value. Pathol Res Pract. 2017;213(5):453-6.

27. Zhou S, Jiang H, Li M, Wu P, Sun L, Liu Y, Zhu K, Zhang B, Sun G, Cao C, et al. Circular RNA hsa_circ_0016070 is associated with pulmonary arterial hypertension by promoting PASMC proliferation. Mol Ther Nucleic Acids. 2019;18:275-84. 
28. Huang Z, Cao Y, Zhou M, Qi X, Fu B, Mou Y, Wu G, Xie J, Zhao J, Xiong W. Hsa_circ_0005519 increases IL-13/IL-6 by regulating hsa-let-7a-5p in CD4(+) T cells to affect asthma. Clin Exp Allergy. 2019;49(8):1116-27.

29. Bachmayr-Heyda A, Reiner AT, Auer K, Sukhbaatar N, Aust S, Bachleitner-Hofmann T, Mesteri I, Grunt TW, Zeillinger R, Pils D. Correlation of circular RNA abundance with proliferation-exemplified with colorectal and ovarian cancer, idiopathic lung fibrosis, and normal human tissues. Sci Rep. 2015;5:8057.

30. Fisher AJ, Cipolla E, Varre A, Gu H, Mickler EA, Vittal R. Potential mechanisms underlying TGF-betamediated complement activation in lung fibrosis. Cell Mol Med Open Access. 2017;3(3). pii: 14.

31. Dai WJ, Qiu J, Sun J, Ma CL, Huang N, Jiang Y, Zeng J, Ren BC, Li WC, Li YH. Downregulation of microRNA-9 reduces inflammatory response and fibroblast proliferation in mice with idiopathic pulmonary fibrosis through the ANO1-mediated TGF-beta-Smad3 pathway. J Cell Physiol. 2019;234(3):2552-65.

32. Sellares J, Veraldi KL, Thiel KJ, Cardenes N, Alvarez D, Schneider F, Pilewski JM, Rojas M, FeghaliBostwick CA. Intracellular heat shock protein 70 deficiency in pulmonary fibrosis. Am J Respir Cell Mol Biol. 2019;60(6):629-36.

33. Sen $N$, Weingarten $M$, Peter $Y$. Very late antigen- 5 facilitates stromal progenitor cell differentiation into myofibroblast. Stem Cells Transl Med. 2014;3(11):1342-53.

34. Liu B, Jiang T, Hu X, Liu Z, Zhao L, Liu H, Liu Z, Ma L. Downregulation of microRNA30a in bronchoalveolar lavage fluid from idiopathic pulmonary fibrosis patients. Mol Med Rep. 2018;18(6):5799-806.

35. Qu H, Liu L, Liu Z, Qin H, Liao Z, Xia P, Yang Y, Li B, Gao F, Cai J. Blocking TBK1 alleviated radiationinduced pulmonary fibrosis and epithelial-mesenchymal transition through Akt-Erk inactivation. Exp Mol Med. 2019;51(4):42.

36. Baran CP, Fischer SN, Nuovo GJ, Kabbout MN, Hitchcock CL, Bringardner BD, McMaken S, Newland CA, Cantemir-Stone CZ, Phillips GS, et al. Transcription factor ets-2 plays an important role in the pathogenesis of pulmonary fibrosis. Am J Respir Cell Mol Biol. 2011;45(5):999-1006.

37. Lu Y, Zhang T, Shan S, Wang S, Bian W, Ren T, Yang D. MiR-124 regulates transforming growth factorbeta 1 induced differentiation of lung resident mesenchymal stem cells to myofibroblast by repressing Wnt/beta-catenin signaling. Dev Biol. 2019;449(2):115-21.

38. Jin J, Zhai HF, Jia ZH, Luo XH. Long non-coding RNA HOXA11-AS induces Type I Collagen synthesis to keloid formation via sponging miR-124-3p and activating Smad5 Signaling. Am J Physiol Cell Physiol. 2019;317(5):C1001-C1010.

39. Yang S, Liu X, Li X, Sun S, Sun F, Fan B, Zhao S. MicroRNA-124 reduces caveolar density by targeting caveolin-1 in porcine kidney epithelial PK15 cells. Mol Cell Biochem. 2013;384(1-2):213-9.

40. Zhou H, Gao L, Yu ZH, Hong SJ, Zhang ZW, Qiu ZZ. LncRNA HOTAIR promotes renal interstitial fibrosis by regulating Notch1 pathway via the modulation of miR-124. Nephrology (Carlton). 2019;24(4):472-80. 
41. Cui M, Wang J, Li Q, Zhang J, Jia J, Zhan X. Long non-coding RNA HOXA11-AS functions as a competing endogenous RNA to regulate ROCK1 expression by sponging miR-124-3p in osteosarcoma. Biomed Pharmacother. 2017;92:437-44.

42. Chen G, Shi Y, Zhang Y, Sun J. CircRNA_100782 regulates pancreatic carcinoma proliferation through the IL6-STAT3 pathway. Onco Targets Ther. 2017;10:5783-94.

43. Henn D, Abu-Halima M, Wermke D, Falkner F, Thomas B, Kopple C, Ludwig N, Schulte M, Brockmann MA, Kim YJ, et al. MicroRNA-regulated pathways of flow-stimulated angiogenesis and vascular remodeling in vivo. J Transl Med. 2019;17(1):22.

44. Tang Q, Yuan Q, Li H, Wang W, Xie G, Zhu K, Li D. miR-223/Hsp70/JNK/JUN/miR-223 feedback loop modulates the chemoresistance of osteosarcoma to cisplatin. Biochem Biophys Res Commun. 2018;497(3):827-34.

45. Ji X, Wu B, Fan J, Han R, Luo C, Wang T, Yang J, Han L, Zhu B, Wei D, et al. The anti-fibrotic effects and mechanisms of microRNA-486-5p in pulmonary fibrosis. Sci Rep. 2015;5:14131.

46. Shentu TP, Huang TS, Cernelc-Kohan M, Chan J, Wong SS, Espinoza CR, Tan C, Gramaglia I, van der Heyde $\mathrm{H}$, Chien $\mathrm{S}$, et al. Thy-1 dependent uptake of mesenchymal stem cell-derived extracellular vesicles blocks myofibroblastic differentiation. Sci Rep. 2017;7(1):18052.

47. Yang IV, Luna LG, Cotter J, Talbert J, Leach SM, Kidd R, Turner J, Kummer N, Kervitsky D, Brown KK, et al. The peripheral blood transcriptome identifies the presence and extent of disease in idiopathic pulmonary fibrosis. PLoS One. 2012;7(6):e37708.

48. Arthur G, Bradding P. New developments in mast cell biology: Clinical implications. Chest. 2016;150(3):680-93.

49. Li R, Bernau K, Sandbo N, Gu J, PreissI S, Sun X. Pdgfra marks a cellular lineage with distinct contributions to myofibroblasts in lung maturation and injury response. Elife. 2018;7. pii: e36865.

50. Gokey JJ, Sridharan A, Xu Y, Green J, Carraro G, Stripp BR, Perl AT, Whitsett JA. Active epithelial Hippo signaling in idiopathic pulmonary fibrosis. JCI Insight. 2018;3(6). pii: 98738.

\section{Figures}


A

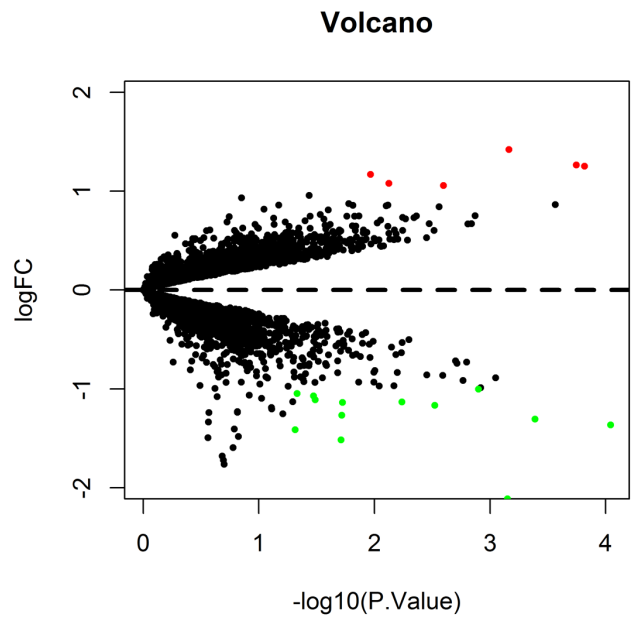

B

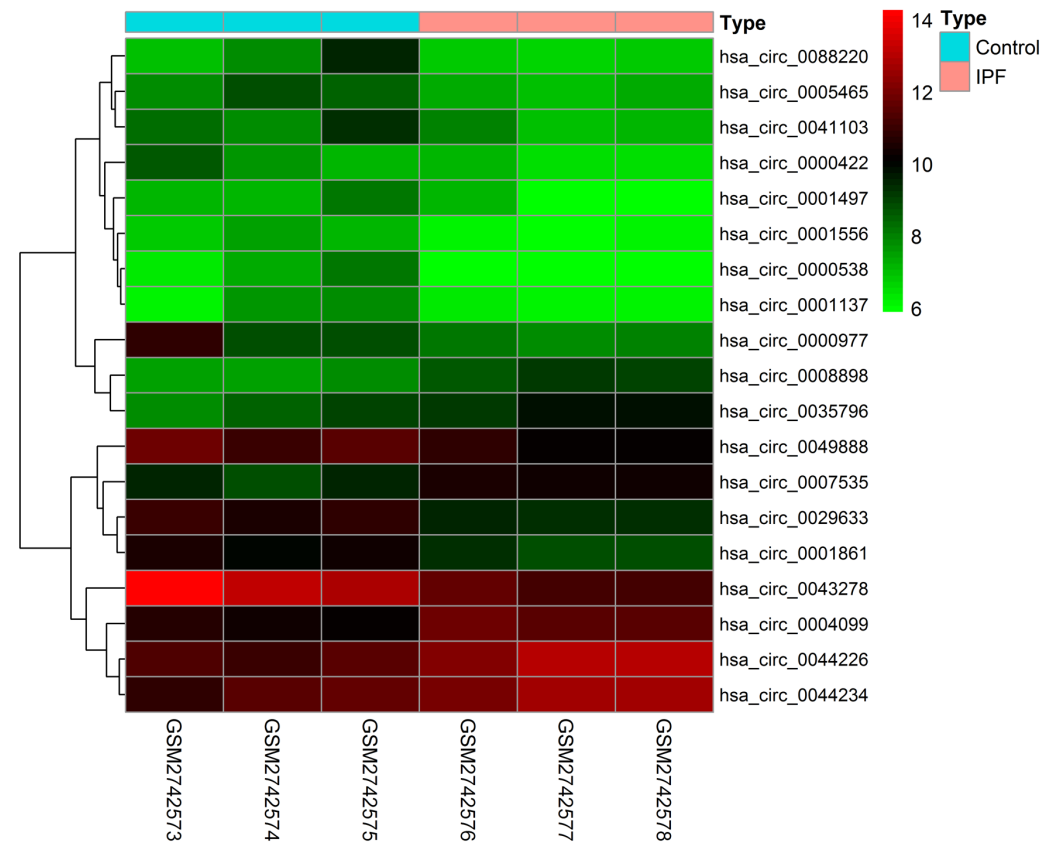

\section{Figure 1}

Differentially expressed circRNA profiles in IPF: A A volcano plot shows the differentially expressed circRNAs between IPF group and control group. Red and green points represent the up-regulated and down-regulated circRNAs, respectively. B Hierarchical cluster analysis reveals the expression profiles of the dysregulated circRNAs between IPF group and control group.

A

MRE (microRNA response element)

RBP (RNA binding protein)

$\mathrm{ORF}$ (open reading frame)

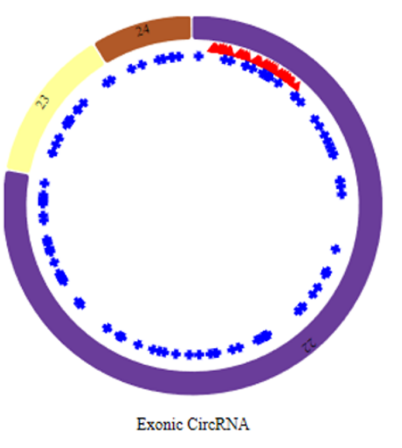

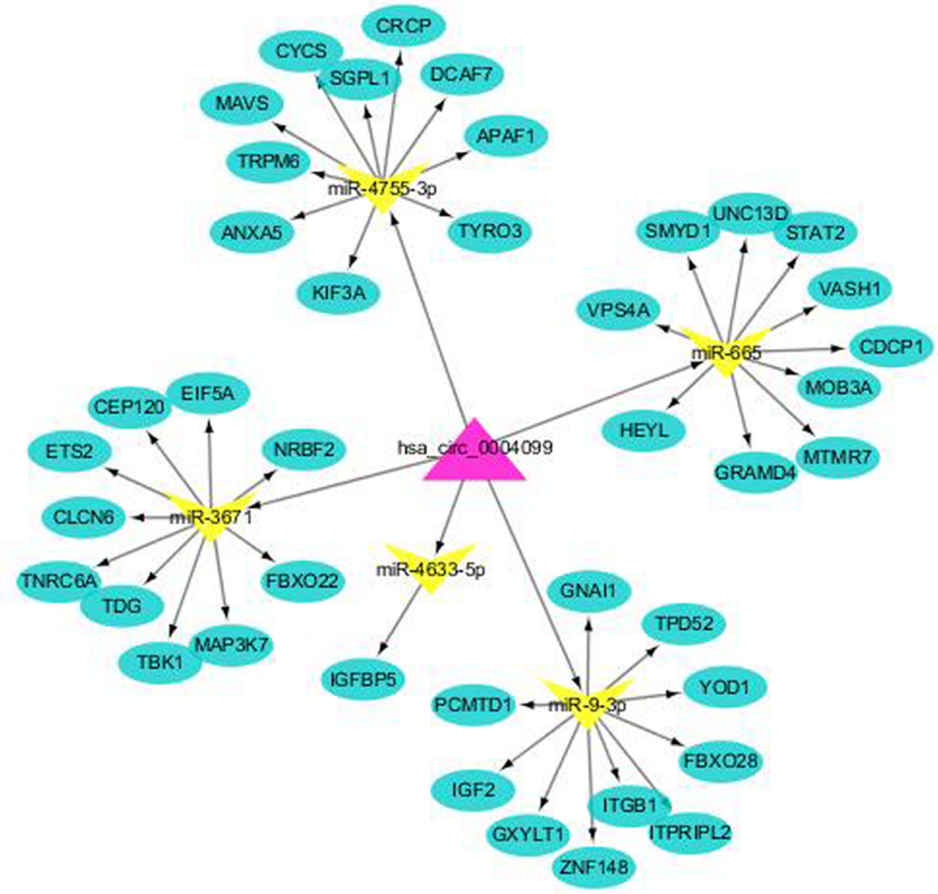

Figure 2 
A schematic diagram of the structure and circRNA-miRNA-mRNA interaction network for hsa_circ_0004099. A A schematic diagram of the structure shows the functional area of hsa_circ_0004099. B Cytoscape software presents putative circRNA-miRNA-mRNA interaction network of hsa_circ_0004099.

A

MRE (microRNA response element)

RBP (RNA binding protein)

ORF (open reading frame)

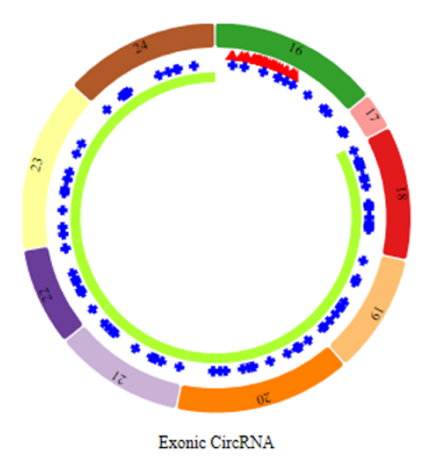

B

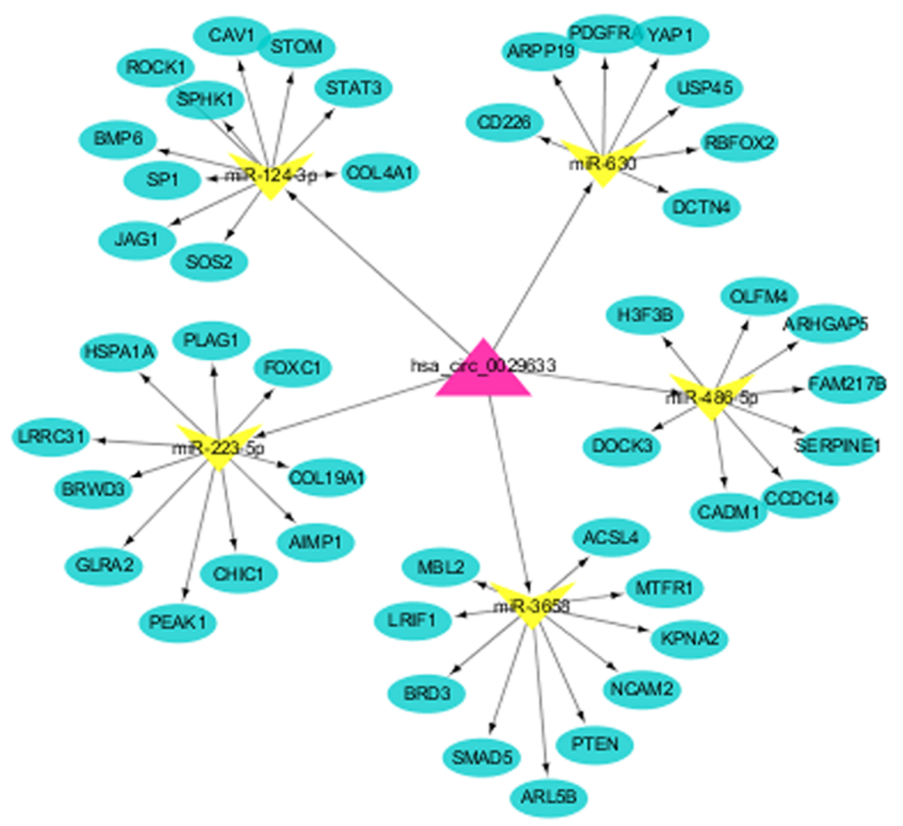

\section{Figure 3}

A schematic diagram of the structure and circRNA-miRNA-mRNA interaction network for hsa_circ_0029633. A A schematic diagram of the structure shows the functional area of hsa_circ_0029633. B Cytoscape software presents putative circRNA-miRNA-mRNA interaction network of hsa_circ_0029633. 
A

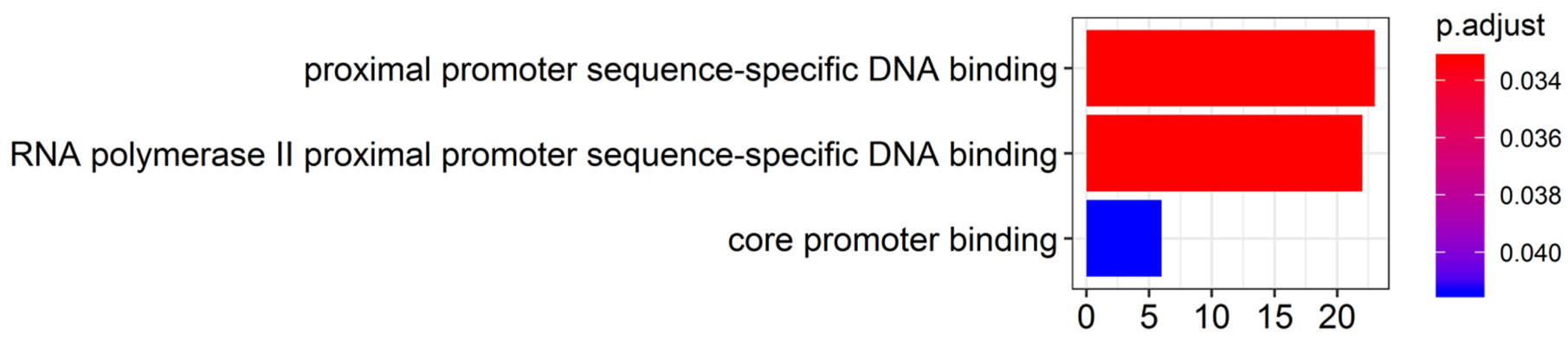

B

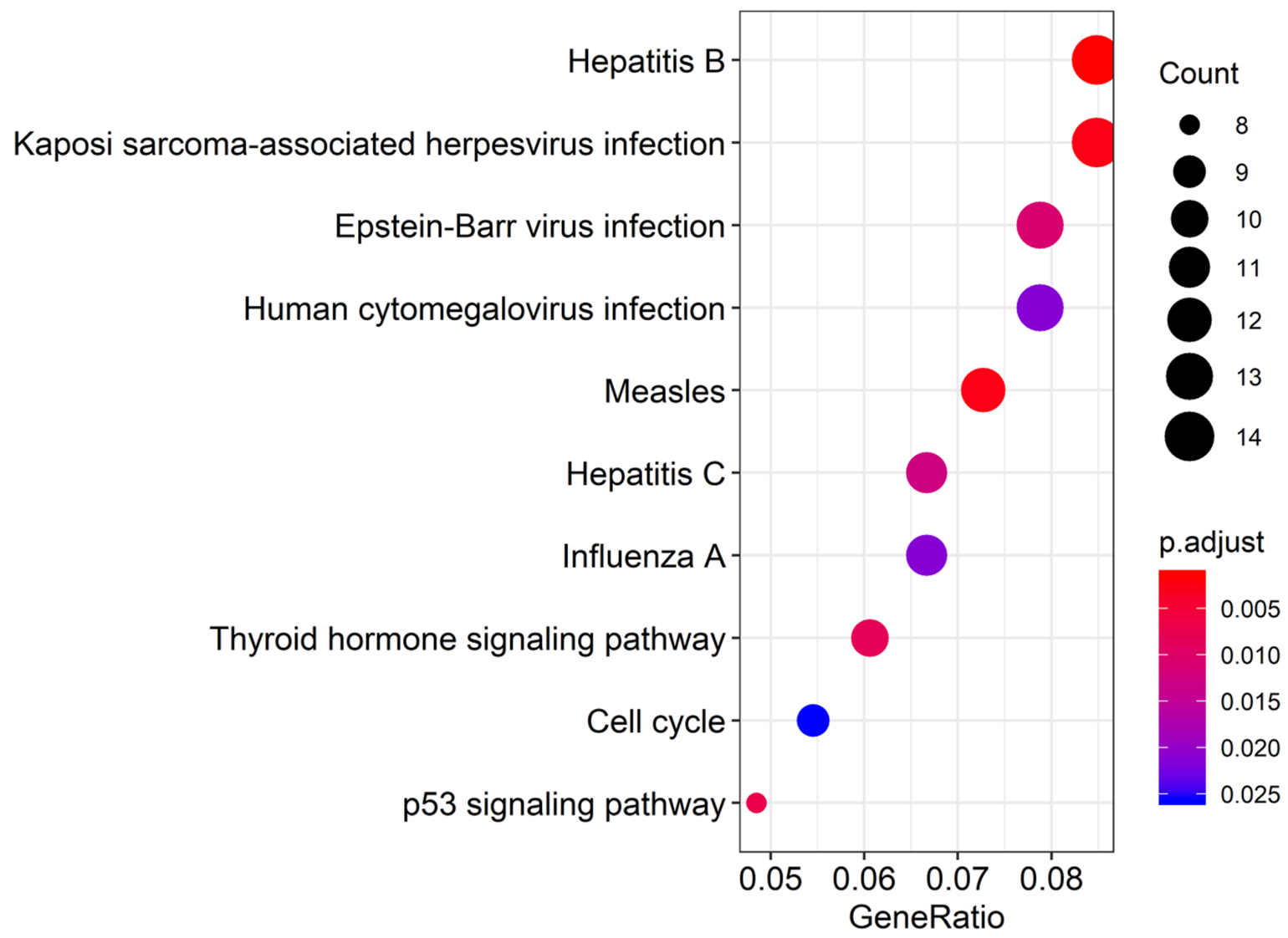

\section{Figure 4}

GO and KEGG enrichment analysis for target genes of hsa_circ_0004099. A Molecular function for target genes of hsa_circ_0004099 was identified by GO enrichment analysis. B Pathways for target genes of hsa_circ_0004099 were verified by KEGG enrichment analysis. 


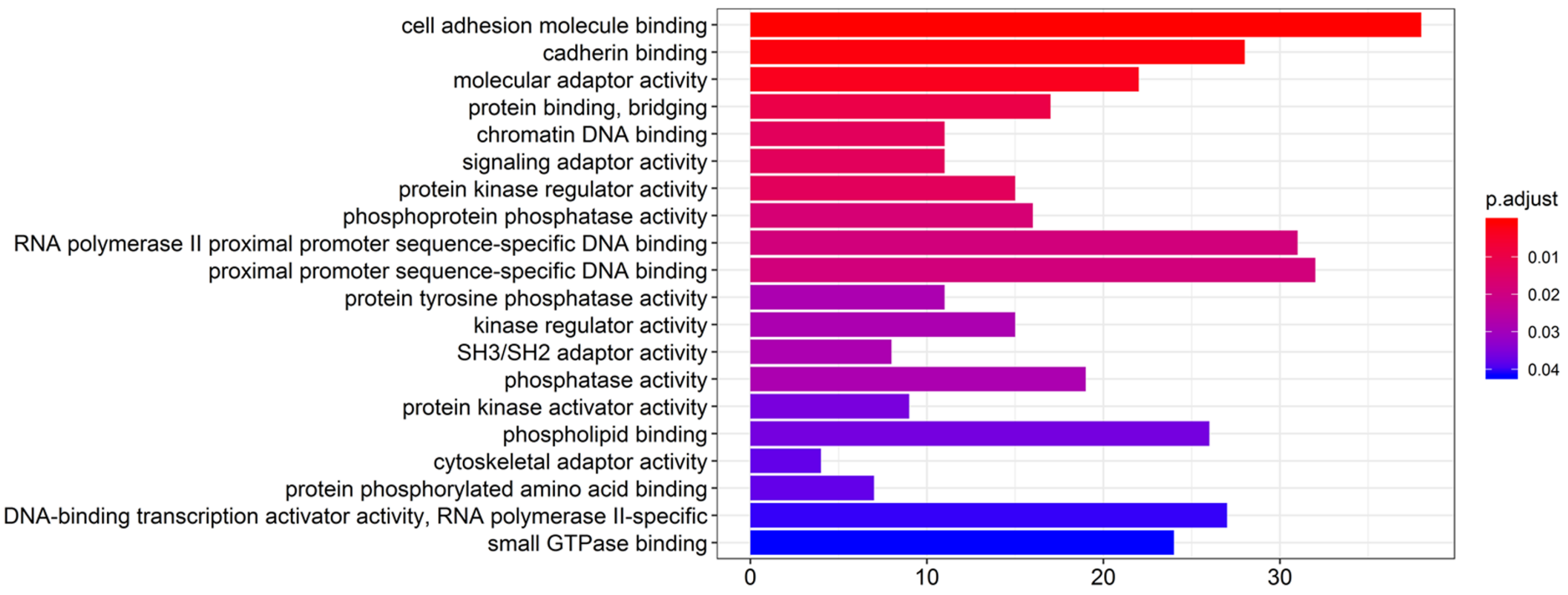

B

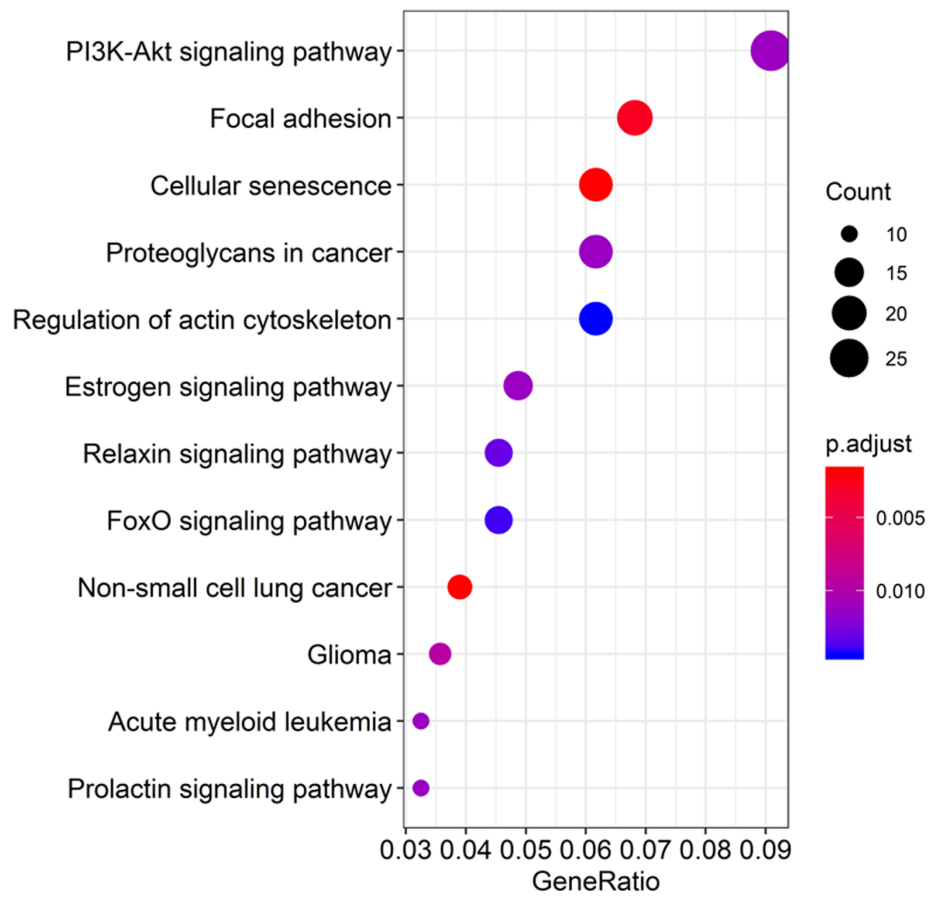

Figure 5

GO and KEGG enrichment analysis for target genes of hsa_circ_0029633. A Molecular function for target genes of hsa_circ_0029633 was identified by GO enrichment analysis. B Pathways for target genes of hsa_circ_0029633 were verified by KEGG enrichment analysis.

\section{Supplementary Files}

This is a list of supplementary files associated with this preprint. Click to download.

- S1.tif 
- S7.tif

- S6.tif

- S8.tif

- S5.tif

- S2.tif

- S4.tif

- S3.tif 